\title{
Evaluation of ferric carboxymaltose treatment efficacy in women with postpartum iron deficiency anemia
}

\author{
๑Mustafa Tekin, @Navdar Doğuş Uzun @Fulya Uzun \\ Mardin State Hospital Obstetrics and Gynecology Department, Mardin, Turkey
}

Cite this article as: Tekin M, Uzun ND, Uzun F. Evaluation of ferric carboxymaltose treatment efficacy in women with postpartum iron deficiency anemia. J Health Sci Med 2021; 4(1): 23-27.

\begin{abstract}
Aim: Most women in the Turkish population have iron deficiency anemia. Particularly among the pregnant women, its rate increases. In this study, we aimed to evaluate the efficacy of intravenous ferric carboxymaltose administration in anemic women in the postpartum period.

Material and Method: The hemoglobin ( $\mathrm{Hb})$ and hematocrit (Htc) values of 64 patients who received intravenous ferric carboxymaltose treatment between January 1, 2020 and July 1, 2020 in Mardin State Hospital, Gynecology and Obstetrics Clinic were retrospectively evaluated. Patients who received intravenous iron carboxymaltose treatment for postpartum iron deficiency anemia were compared after treatment. The length of stay in the hospital and whether the patient priorly received an erythrocyte suspension were evaluated.

Results: Patients who received intravenous (IV) ferric carboxymaltose mostly due to anemia after cesarean section and normal delivery (NSD) were included in the study. Pregnancy week and hospitalization duration means were significantly higher in the $\mathrm{C} / \mathrm{S}$ group $(\mathrm{p}<0.05)$. A statistically significant increase was observed in $\mathrm{Hb}$ and $\mathrm{Htc}$ values after intravenous iron treatment administered after cesarean delivery. $(\mathrm{p}<0.05)$. The birth rate was significantly higher in the young and normal delivery groups $(\mathrm{p}<0.01)$. A significant increase in control hemoglobin values was observed after 10 days in patients who received intravenous iron therapy.
\end{abstract}

Conclusion: During the postpartum period, IV ferric carboxymaltose use for moderate anemia is safe and efficient.

Keywords: Anemia, ferric carboxymaltose, hemoglobin, iron deficiency anemia, intravenous iron

\section{INTRODUCTION}

Iron deficiency anemia is an important public health problem. It develops in cases where the need for elemental iron required for hemoglobin synthesis increases, such as during pregnancy or the postoperative period, in other words, when negative iron balance occurs in the body. The World Health Organization has stated that female individuals with hemoglobin values below $12 \mathrm{~g} / \mathrm{dl}$ have iron deficiency anemia (1). Although the rate is higher in developing countries, considering the general population, the rate of iron deficiency is approximately $25 \%$ (2). The World Health Organization states that the rate of iron deficiency anemia during pregnancy increases even more. Iron deficiency anemia should be corrected after delivery in women, for it is responsible for $20-40 \%$ of maternal deaths after cesarean section or normal spontaneous vaginal delivery (3).
If iron deficiency is detected in a woman, it should be treated. It is essential to treat this condition quickly and safely. Oral iron should be preferred to intravenous iron treatment, except in special cases, because it is safe and cheap. In oral iron treatment, side effects such as nausea, vomiting, peptic complaints, gastroesophageal regurgitation, diarrhea, constipation, stool discoloration affect the treatment and may lead to discontinuation $(4,5)$. Accompanying symptoms such as tachycardia, dizziness and headache in severe anemias require urgent treatment. Intravenous iron therapy may be appropriate in patients who cannot tolerate oral therapy or need urgent treatment $(6,7)$.

In this study, we aimed to determine the effectiveness of the treatment with intravenous ferric carboxymaltose and control hemogram and hematocrit values after 10 days in patients with hemogram values below $9 \mathrm{~g} / \mathrm{ml}$ 
after cesarean and normal delivery. Patients were also asked to evaluate their hospital stay. Practical and current treatment approaches for anemia, which must be treated after birth, were evaluated.

\section{MATERIAL AND METHOD}

Ethics committee approval was received from Mardin Provincial Health Directorate on 27.08.2020 with the permission number 806.02.02-E.1333. All procedures were performed adhered to the ethical rules and the Helsinki Declaration of Principles.

Intravenous ferric carboxymaltose was administered in Mardin State Hospital, Gynecology and Obstetrics Clinic between 1 January 2020 and 15 July 2020 to patients with hemoglobin values below $9 \mathrm{mg} / \mathrm{dL}$, who had given birth with caesarian section or via spontaneous vaginal route, who were incidentally determined to have anemia during routine outpatient visits. Those who had chronic anemia before, those who received intravenous iron treatment during pregnancy, those with anemia not caused by iron deficiency, those with severe liver disease, those with known allergy to any substance contained in the intravenous ferric carboxymaltose preparation were not included in the study. Control hemogram and hematocrit values obtained after 10 days were compared with pretreatment values. Oral iron therapy was continued during these 10 days. A total of 64 anemic women with postpartum period were included in this retrospective cohort study. The gestational status of the patients, the weeks of gestation of the pregnant women, whether they underwent an operation, whether blood was priorly transfused, control hemogram and hematocrit values before and after treatment, and duration of hospital stay were analyzed. Each patient was given $1000 \mathrm{mg}$ intravenous ferric carboxymaltose in $250 \mathrm{ml}$ of $0.9 \%$ isotonic for 15 minutes. None of the patients experienced allergies, rash, itching, anaphylaxis or similar side effects.

\section{Statistical Methods}

Scale parameters were described with mean and standard deviations, whereas nominal parameters were described with frequency analysis. Kolmogorov Smirnov Test was used for normality distribution test of scale parameters. Independent samples T-Test was used for differences between normally distributed parameters, and Mann Whitney $U$ test was used to evaluate differences between non-normally distributed parameters. Chi Square Test was used for comparison of categorical parameters. Spearman's rho correlation was used for relational analysis. SPSS 17.0 for Windows was used, and analysis was performed with 95\% confidence interval and an alpha level of 0.05 .

\section{RESULTS}

Some baseline characteristics of patients are presented in the Table 1.

\begin{tabular}{|c|c|c|c|}
\hline Parameters & $\mathrm{C} / \mathrm{S}(\mathrm{n}=42)$ & $\operatorname{NSD}(n=22)$ & $\mathbf{p}$ \\
\hline Age, mean $\pm S D$ & $29.24 \pm 6.48$ & $28.73 \pm 5.55$ & $0.754^{\mathrm{a}}$ \\
\hline Pregnancy week, mean \pm SD & $36.40 \pm 3.76$ & $31.68 \pm 6.06$ & $0.001^{\mathrm{b}}$ \\
\hline ES, n (\%) & $9(21.4)$ & $3(13.6)$ & $0.439^{\circ}$ \\
\hline ES Amount, mean \pm SD & $3.00 \pm 1.12$ & $1.67 \pm 0.58$ & $0.082^{\mathrm{a}}$ \\
\hline $\begin{array}{l}\text { Hospitalization duration, } \\
\text { mean } \pm \mathrm{SD} \text {, (day) }\end{array}$ & $2.12 \pm 1.04$ & $1.14 \pm 0.35$ & $0.000^{\mathrm{b}}$ \\
\hline
\end{tabular}

Pregnancy week and hospitalization duration means were significantly higher in the $\mathrm{C} / \mathrm{S}$ group $(\mathrm{p}<0.05)$. Age, ES transfusion and its amount were similar between patient groups $(\mathrm{p}>0.05)$.

Initial and final $\mathrm{Hb}$ and $\mathrm{Htc}$ values and difference analysis results between patient groups are presented in Table 2.

Table 2. Initial and final $\mathrm{Hb}$ and $\mathrm{HTC}$ values and difference analysis results between patient groups

\begin{tabular}{|lccc|}
\hline Parameters, mean \pm SD & $\mathbf{C} / \mathbf{S}(\mathbf{n}=\mathbf{4 2})$ & $\mathbf{N S D}(\mathbf{n}=\mathbf{2 2})$ & $\mathbf{p}^{\mathbf{a}}$ \\
\hline Initial Hb & $7.93 \pm 0.58$ & $8.00 \pm 0.51$ & 0.598 \\
Initial HTC & $24.95 \pm 2.06$ & $25.50 \pm 1.82$ & 0.301 \\
Final Hb & $10.91 \pm 0.96$ & $10.51 \pm 0.78$ & 0.093 \\
Final HTC & $35.26 \pm 2.85$ & $33.31 \pm 2.57$ & 0.009 \\
\hline \multicolumn{4}{|l}{ a. Independent Samples T-Test, SD: Standard Deviation. } \\
\hline
\end{tabular}

Final Htc value was significantly higher in the C/S group $(\mathrm{p}<0.05)$. Initial $\mathrm{Hb}, \mathrm{Htc}$ and final $\mathrm{Hb}$ differences between groups were insignificant ( $\mathrm{p}>0.05)$. Final Htc distribution of patient groups is shown in the Figure 1.

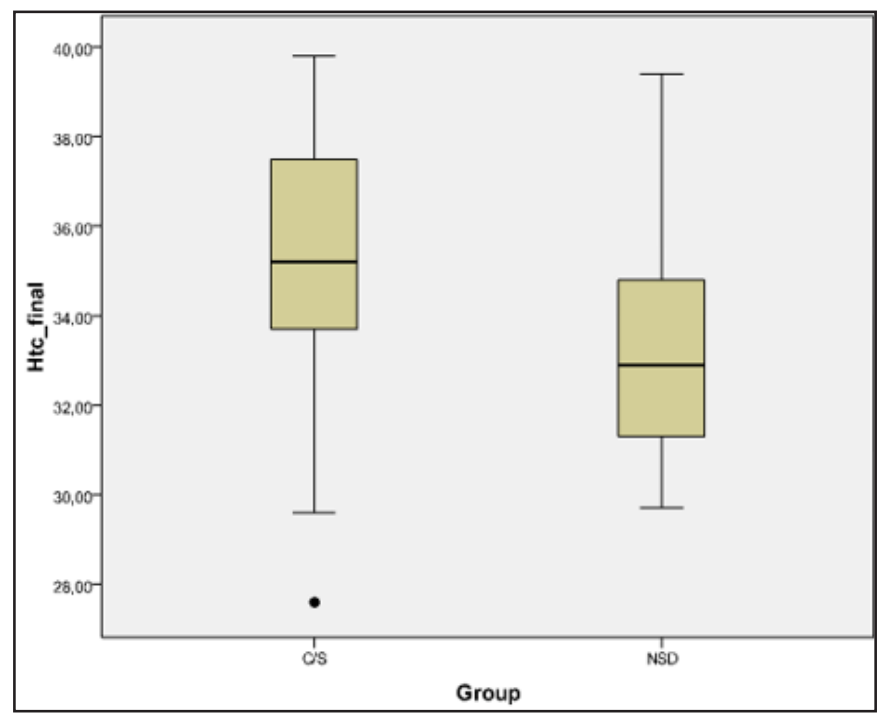

Figure 1. Final HTC distribution of patient groups 
According to Figure 1, both mean and range of final Htc of C/S patients were higher those of NSD patients.

Spearman's rho correlation analysis results of baseline $\mathrm{Hb}$ and Htc values are presented in Table 3.

Table 3. Spearman's rho correlation analysis results between baseline characteristics with $\mathrm{Hb}$ and HTC

\begin{tabular}{|lcccc|}
\hline \multirow{2}{*}{ Parameters } & \multicolumn{2}{c}{ C/S $(\mathbf{n}=\mathbf{4 2})$} & \multicolumn{2}{c|}{ NSD $(\mathbf{n}=22)$} \\
\cline { 2 - 5 } & Final Hb & Final HTC & Final Hb & Final HTC \\
\hline Age & 0.029 & 0.064 & $-0.555^{* *}$ & -0.331 \\
Pregnancy week & 0.191 & 0.167 & 0.188 & 0.177 \\
ES & 0.283 & 0.141 & -0.157 & -0.178 \\
ES Amount & 0.291 & 0.158 & 0.500 & 0.866 \\
$\begin{array}{l}\text { Hospitalization } \\
\text { duration }\end{array}$ & -0.033 & -0.086 & 0.178 & 0.230 \\
\hline${ }^{* *} \mathrm{p}<0.01$ & & & & \\
\hline
\end{tabular}

Only final $\mathrm{Hb}$ and age relation in NSD group was statistically and negatively significant $(\mathrm{p}<0.01)$. On the other hand, this correlation was insignificant in the $\mathrm{C} / \mathrm{S}$ group ( $p>0.05)$. Pregnancy week, erythrocyte suspension (ES) transfusion, its amount and hospitalization duration were not correlated with final $\mathrm{Hb}$ and $\mathrm{Htc}$ in both groups $(\mathrm{p}>0.05)$.

\section{DISCUSSION}

Iron deficiency anemia is confirmed by a measurable hemoglobin concentration of less than $12 \mathrm{~g} / \mathrm{dl}$ for women or a ferritin level of less than $30 \mathrm{ml} /$ ng (8). Erythrocytic changes such as hypochromia, microcytosis, anisocytosis and poikilocytosis can be seen in the examination of the blood sample with light microscopy. As a result of these changes, a series of symptoms such as fatigue, shortness of breath, vertigo, syncope, PICA, palpitations, angina, headache, cognitive dysfunction, and restless leg syndrome may occur due to the inadequate supply of tissues (8). It is known that intravenous iron use is superior to oral use in pregnancy, chronic renal failure, and inflammatory bowel disease (9-14). Oral iron therapy is also associated with frequent gastrointestinal side effects, and this is one of the most important reasons for non-compliance (15).

Ferric carboxymaltose was approved by the European Medicines Agency in 2007 for use in iron deficiency anemia (16). In July 2013, intravenous ferric carboxymaltose was approved by the United States Food and Drug Administration (FDA) for the treatment of iron deficiency anemia in adult patients with inadequate response to oral iron therapy.

During the Covid-19 pandemic, the operation room at Mardin State Hospital was reserved only for emergency cases. While cesarean section was performed in 42 of the patients included in our study, 22 patients had a normal delivery. Before the administration of intravenous ferric carboxymaltose, 12 units of erythrocyte suspension was required: Following caesarian section in 42 patients, following had a hysterectomy in 1 patient.

In this study, when $\mathrm{Hb}$ and Htc levels were examined before and after intravenous ferric carboxymaltose administration, a statistically significant increase was observed in both variables after cesarean operations $(\mathrm{p}<0.05)$. An increase was observed in mean final $\mathrm{Hb}(10.91 \pm 0.96 \mathrm{mg} / \mathrm{dL})(3 \mathrm{mg} / \mathrm{dL}-$ fold $)$ and final Htc values (\%35.26 \pm 2.85$)$. During the pandemic, there were difficulties in obtaining erythrocyte suspension. All patients were prescribed oral iron treatment to be used for 1 month following discharge. Although the number of patients participating in the current study population is small, our study may be a modest guiding point for the treatment process of severe anemia preand postoperatively during the pandemic.

Richard F. Pollock et al. found a significant improvement in the initial $\mathrm{Hb}$ value after treatment, as in our study (8). They recommended intravenous iron treatment without concern in patients who cannot tolerate oral iron therapy (8). Although medical and economic considerations regarding the administration of erythrocyte suspension (RBC) advocate restricting its use, it is widely used for the correction of anemia (17). It has been shown that RBC transfusion significantly increases morbidity and mortality, and negatively affects the remaining survival after treatment in colorectal cancer patients (18). Infection and autoimmune events can also occur after RBC transfusion. Moreover, RBC transfusion increases the risk of nosocomial infections and is highly associated with increased mortality in hospitalized patients (19). In anemia, erythrocyte increase will be attained within a brief period with iron infusion only, and treatment success will be achieved.

The cost-effectiveness of intravenous iron therapy was evaluated especially in UK publications. In a 5-center study conducted on surgical patients in Europe and the United States, RBC transfusion was not found to be cost-effective (20). In a study conducted in Sweden, it was reported that the side effects developing after RBC transfusion and the cost resulting from the increase in the hospitalization of the patients constituted $35 \%$ of the total treatment cost (6). In our study, after cesarean operation, the average length of stay after intravenous iron treatment was $2.12 \pm 1.04$ day, and significantly higher than the NDS group. The Ministry of Health of The Republic of Turkey published a guideline, recommending at least 48 hours of hospital stay following caesarian delivery. 
We determined that as gestational week increased, $\mathrm{Hb}$ value decreased significantly, due to the physiological increase in maternal intravascular volume. In addition, iron uptake in the placenta is high, regardless of the $\mathrm{Hb}$ level, the iron absorbed by the fetus from the circulation continues unabated. Therefore, as the gestational week progresses, the $\mathrm{Hb}$ values decrease.

It has been shown that intravenously administered iron increases Hb levels more effectively than oral iron (21). Some studies offer intravenous carboxymaltose as an additional treatment option in the treatment of iron deficiency anemia (22). Serious acute hypersensitivity reactions to intravenous iron formulations are rare but may occur, and most allergic reactions seen in the past were due to the high-molecular iron dextran complex (23). Ferric carboxymaltose is administered in a single visit. Considering the patient and length of stay, it promises a shorter treatment period for patients diagnosed with anemia (24). However, anaphylaxis, allergy and not being used in the first trimester of pregnancy are the limitations of this treatment.

This current study has some limitations. First of all, our study population is relatively small. Moreover, this study was a single center, retrospective research.

\section{CONCLUSION}

As disease awareness of iron deficiency anemia continues to develop over the next few years and the benefit-risk ratio encouraging the patients from different populations to comply is considered, treatment options for iron supplementation will be open to evolution and change. Future modeling efforts may further clarify the frequency and consequences of events such as side effects and allergies, in addition to the initial administration costs of iron formulations.

\section{ETHICAL DECLARATIONS}

Ethics Committee Approval: Ethics committee approval was received from Mardin Provincial Health Directorate on 27.08.2020 with the permission number 806.02.02E.1333.

Informed Consent: Because the study was designed retrospectively, no written informed consent form was obtained from patients.

Referee Evaluation Process: Externally peer-reviewed.

Conflict of Interest Statement: The authors have no conflicts of interest to declare.

Financial Disclosure: The authors declared that this study has received no financial support.

Author Contributions: All of the authors declare that they have all participated in the design, execution, and analysis of the paper, and that they have approved the final version.

\section{REFERENCES}

1. Moore RA, Gaskell H, Rose P, Allan J. Meta-analysis of efficacy and safety of intravenous ferric carboxymaltose (Ferinject) from clinical trial reports and published trial data. BMC Blood Disord 2011; 11: 4.

2. WHO. Haemoglobin concentrations for the diagnosis of anaemia and assessment of severity. Vitamin and Mineral Nutrition Information System. Geneva, World Health Organization, 2011 (WHO/NMH/NHD/MNM/11.1) (http://www.who.int/vmnis/ indicators/haemoglobin. pdf, accessed [25.09.2020]).

3. Prakash S, Yadav K. Maternal anemia in pregnancy: an overview. IJPPR 2015; 4: 164-79.

4. Johnson-Wimbley TD, Graham DY. Diagnosis and management of iron deficiency anemia in the 21st century. Therap Adv Gastroenterol 2011; 4: 177-84.

5. Percy L, Mansour D, Fraser I. Iron deficiency and iron deficiency anaemia in women. Best Pract Res Clin Obstet Gynaecol 2017; 40: $55-67$.

6. Glenngard AH, Persson U, Soderman C. Costs associated with blood transfusions in Sweden-the societal cost of autologous, allogeneic and perioperative RBC transfusion. Transfus Med 2005; 15: 295-306.

7. Low MS, Grigoriadis G. Iron deficiency and new insights into therapy. Med J Aust 2017; 207: 81-7.

8. Pollock RF, Muduma G. A patient-level cost-effectiveness analysis of iron isomaltoside versus ferric carboxymaltose for the treatment of iron deficiency anemia in the United Kingdom. J Med Econ 2020; 23: 751-9. doi:10.1080/13696998.2020.1745535.

9. Avni T, Bieber A, Steinmetz T, Leibovici L, Gafter-Gvili A. Treatment of anemia in inflammatory bowel disease--systematic review and meta-analysis. PLoS One 2013; 8: e75540.

10. Bonovas S, Fiorino G, Allocca $\mathrm{M}$, et al. Intravenous Versus Oral Iron for the Treatment of Anemia in Inflammatory Bowel Disease: A Systematic Review and Meta-Analysis of Randomized Controlled Trials. Medicine (Baltimore) 2016; 95: e2308.

11. Avni T, Leibovici L, Gafter-Gvili A. Iron supplementation for the treatment of chronic heart failure and iron deficiency: systematic review and meta-analysis. Eur J Heart Fail 2012; 14: 423-9.

12. O'Lone EL, Hodson EM, Nistor I, Bolignano D, Webster AC, Craig JC. Parenteral versus oral iron therapy for adults and children with chronic kidney disease. Cochrane Database Syst Rev 2019; 2: CD007857.

13.Susantitaphong P, Alqahtani F, Jaber BL. Efficacy and safety of intravenous iron therapy for functional iron deficiency anemia in hemodialysis patients: a meta-analysis. Am J Nephrol 2014; 39: 130-41.

14. Reveiz L, Gyte GM, Cuervo LG, Casasbuenas A. Treatments for iron-deficiency anaemia in pregnancy. Cochrane Database Syst Rev 2011; 10: CD003094.

15. Lindgren S, Wikman O, Befrits $\mathrm{R}$, et al. Intravenous iron sucrose is superior to oral iron sulphate for correcting anaemia and restoring iron stores in IBD patients: A randomized, controlled, evaluator-blind, multicentre study. Scand J Gastroenterol 2009; 44: 838-45.

16. Linda M Mundy, Stefan Wohlfeil ; A comment on the comparative safety of intravenous ferumoxytol versus ferric carboxymaltose in iron deficiency anemia ; Am J Hematol 2018; 93: 231-2.

17. Hreinsson JP, Jonasson JG, Bjornsson ES. Bleeding-related symptoms in colorectal cancer: a 4-year nationwide populationbased study. Aliment Pharmacol Ther 2013; 39: 77-84.

18. Auerbach M, Macdougall IC. Safety of intravenous iron formulations: facts and folklore. Blood Transfus 2014; 12: 296-300.

19. Marik PE, Corwin HL. Efficacy of red blood cell transfusion in the critically ill: a systematic review of the literature. Crit Care Med 2008; 36: 2667-74. 
20. Shander A, Hofmann A, Ozawa S, Theusinger OM, Gombotz H, Spahn DR. Activity-based costs of blood transfusions in surgical patients at four hospitals. Transfusion 2010; 50: 753-65.

21. Kidney Disease: Improving Global Outcomes (KDIGO). KDIGO clinical practice guideline for anemia in chronic kidney disease. Kidney Int Suppl 2012; 2: 280-335.

22.Breymann C, Honegger C, Hösli I, Surbek D. Diagnosis and treatment of iron-deficiency anaemia in pregnancy and postpartum. Arch Gynecol Obstet 2017; 296: 1229-34.

23. Macdougall IC, Vernon K. Complement activation-related pseudoallergy: a fresh look at hypersensitivity reactions to intravenous iron. Am J Nephrol 2017; 45: 60-2.

24. Kant S, Kaur R, Ahamed F, Singh A, Malhotra S, Kumar R. Effectiveness of intravenous ferric carboxymaltose in improving hemoglobin level among postpartum women with moderate-tosevere anemia at a secondary care hospital in Faridabad, Haryana - An interventional study. Indian J Public Health. 2020; 64: 16872 